\title{
Assessing Learning in the Music Classroom
}

\author{
By Paul R. Lehman
}

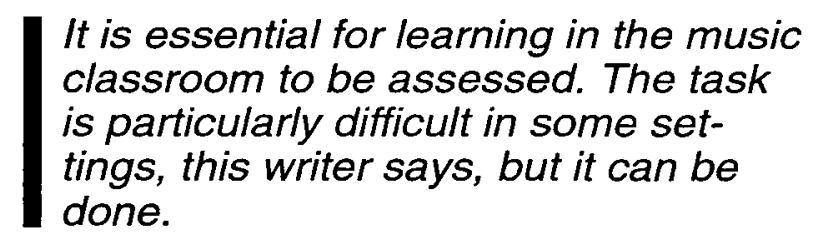

D

o the music teachers in your school resist the idea of assessing their students' work? Many seem to, but look again. After all, they put their bands, orchestras, and choruses on public display regularly in concerts, knowing that the audiences will judge how well the groups perform. Many teachers send these groups, along with student soloists and small ensembles, to contests or competition festivals every year for the sole purpose of being assessed.

In no other discipline do teachers go to such lengths to invite evaluation by professional colleagues and approbation from the public. Why, then, are music teachers often perceived as cool to the idea of assessing their students' skills and knowledge?

One answer is that-aside from concerts and contests-they have no measurement instruments with which they are truly comfortable. There are very few standardized tests in music, and not one that is satisfactory for general use in the music classroom or the rehearsal hall. Why haven't broadly useful

Paul R. Lehman is professor and senior associate dean of the School of Music at the University of Michigan, Ann Arbor, and past president of the Music Educators National Conference. 
standardized tests in music been developed? Because curricula, standards, and practices vary so widely, and because the near-total lack of music teacher interest in formal testing suggests that there would likely be little market for them.

But their reluctance to jump on the testing bandwagon doesn't mean that music teachers are averse to assessment in principle. They merely object to assessment techniques that may be invalid. They object to assessment instruments that don't reflect their objectives. They object to assessment when the time and effort required are out of proportion to the benefits received.

\section{Why Bother?}

Why should a principal care whether his or her music teachers are concerned with assessment? Because thinking carefully about student assessment forces teachers to think carefully about their objectives. The key to assessment lies in determining the objectives of instruction and designing curricula to achieve them. Every teacher should know exactly what it is that he or she wants the students to know and be able to do. If students have this information, the teacher may not have to do much more.

Why should music teachers themselves care about student assessment? In order to appraise their students' achievement, to appraise their own effectiveness, and to appraise the instructional process. Some music teachers argue that we should test more in order to ensure music a place in the curriculum. They have concluded, perhaps with a touch of cynicism, that what is important is tested and what is tested is important. The corollary is that what is not tested is not important. But it is by no means clear that testing would achieve the result they seek.

In any event, this is not a worthy rationale. Testing in music should be done for the best reasons that we test in other disciplines.

\section{Performing Groups}

Except for general music classes in grades seven and eight, most music instruction in the middle level and the high school takes place in bands, orchestras, and choruses. To most music teachers, the ultimate test of a performing group is how it sounds. Any other evaluation would be superfluous and a waste of time.

Assessing learning by listening to the students make music is not new. It's what music teachers do every day, and have for as long as music has been taught. It doesn't require expensive materials or equipment. It doesn't take time beyond the performance itself. And this assessment is literally performance based. Ironically, what music teachers have been doing for years is just now becoming recognized by the rest of the education profession as the ideal way to evaluate.

But what are the standards for making judgments? Assessment by a teacher of his or her own students 
doesn't generate the norm-based data provided by a standardized test. Still, in the absence of standardized tests, the assessment by a teacher of his or her musical ensemble is probably no less valid than that by a teacher in another discipline of his or her class.

The more formal setting of a contest may provide somewhat better information, and in some school districts considerable importance is attached to the ratings received in contests and competitions. School administrators and the public sometimes view these ratings not only as evidence of what the students are learning, but also as indications of the quality of the school music program.

These inferences are not necessarily valid. The reliability and validity of contest ratings have not been adequately investigated and documented. We know that there can be marked differences in the standards from one contest to another.

Contest ratings tell us nothing about the range and nature of the repertoire being taught. They tell us nothing about how balanced or complete the program is. They don't even tell us whether or not the students can read music, except occasionally when a sight reading component is included. And they tell us nothing about student learning in the school's non-performance offerings. All of us should take steps to discourage excessively broad generalizations within our communities concerning the meaning of contest results.

One of the difficulties in assessing individuals in large performing groups is that the teacher never hears all the students perform individually. How is it possible to assess a student's performance without hearing him or her perform alone? Scheduling an audition with each student would help, but it's typically not done because it would require more time than most teachers consider justifiable.

Some educators have lamented the lack of opportunities in schools for students to work cooperatively and to be assessed on their collaborative efforts, as is often required outside the school. Musical performance provides precisely such an opportunity.

\section{Non-Performance Classes}

Contrary to the views of some music teachers, valid assessment of student learning in non-performance music classes is important and possible. Many teachers develop their own tests for classroom use. Some of these tests are excellent, though the quality varies enormously. Because music involves a broad range of cognitive, affective, and psychomotor behaviors, it can provide a laboratory for devising imaginative solutions to many of the diverse assessment problems encountered in other disciplines.

Assessment in music, as in other fields, is a matter of determining how successful students are in performing the tasks that represent 
the desired skills and knowledge. The evaluator must ensure that the assessment tasks are based on the learning objectives; the objectives are represented by assessment tasks in proportion to their importance rather than in proportion to the ease with which they can be translated into behavior; and the sampling of assessment tasks adequately reflects the universe of possibilities.

\section{Grading Practices}

A discussion of student assessment cannot ignore grading practices because grading is an important aspect of educational reality. In classroom music, as in other disciplines, our current practices tend to be painfully limited. Typically, we focus on paper-and-pencil tests, most often in a multiple-choice format. This narrow approach makes it easy to overlook important skills and knowledge that does not lend itself to such techniques.

Criteria for the various grades should be clearly defined so that students know what they must do for a given grade and what each grade means. Several examples of assessment behaviors not in common use can be found in the music items used in the National Assessment of Educational Progress,

1. The Second Assessment of Music, 1978-79: Released Exercise Set (Denver, Colo.: National Assessment of Educational Progress, 1980). which included music in 1971-72, and again in 1978-79. ${ }^{1}$

Our grading practices in large ensembles (i.e., bands, orchestras, and choruses) are often questionable. Some teachers have developed excellent procedures for grading that are appropriate and wellunderstood by the students. These are probably the exceptions. Many directors grade primarily on the basis of attendance or effort, and the grades tend to be consistently high. This practice, so at odds with the usual practice in other disciplines, is often seen by fellow educators as evidence that there is no serious evaluation in music.

But the mere fact that the grades in a large ensemble tend to be high is not in itself evidence of a lack of serious evaluation. It is important to remember that many of these students have studied their instruments for many years, and that the general level of achievement is very high. The students are all there because they want to be there, and because they enjoy what they are doing. Why else would the marching band member, for example, work so hard for so long, often in darkness, cold, rain, and mud?

It would be unreasonable to expect a grade distribution similar to that in a typical biology or math class, where the students' background, motivation, and levels of involvement are often quite different from those of the students in the band or orchestra. We should remember, too, that the extent to 
which our students learn is a function of our effectiveness as teachers.

\section{The Role of Attendance}

Because of the difficulties in grading individuals in large ensembles, many music teachers rely heavily on attendance in determining the grade. One effect of this practice is to cause college admissions officials to disregard high school grades in music.

Attendance should not be the major determinant of grades. A good grade in chorus or band should reflect achievement in chorus or band, not merely good attendance. Still, some recognition of attendance is reasonable, because attendance is clearly one reflection of the commitment of the individual to the group.

\section{The Role of Effort}

Some music teachers profess to grade heavily on effort, as distinguished from achievement. These teachers recognize that some students have less ability than others and can never achieve at the same level as their more talented classmates. Why should a student be "penalized," they ask, because he or she lacks innate talent?

This sympathy is misplaced. A college admissions officer or a prospective employer has a right to assume that a good grade indicates knowledge and skill in the subject matter. The school curriculum is diverse, and every student will be more successful in some courses than in others. A student with little ability in math cannot expect an "A" merely because he tried very hard.

\section{Attitudes and Values}

One major problem often cited by music teachers is that much of their work centers on attitudes and values, neither of which can be tested satisfactorily. That's true, but it is possible to determine whether students possess specific skills and knowledge associated with those attitudes and values.

In my view, asking students questions about their attitudes and values is largely a waste of time, even if one considers such questions ethically appropriate. The responses to these questions cannot be validated, and we cannot have confidence in them. All we will learn with assurance is whether the student is willing to tell the teacher what it appears that he or she wants to hear.

Overemphasis on affective goals, such as getting kids to like music, is self-defeating. Affective goals are best achieved as by-products of a rigorous, high-quality program. They do not work as primary instructional goals-not only because they don't lend themselves to evaluation, but also because they don't provide the basis for building a curriculum.

If we music teachers consistently use good music, and if we teach well, we need not be concerned about whether our students will like music. Most will. Meanwhile, efforts to ensure that students like the subject matter ought not to shape the 
curriculum in music any more than it should in English or history.

Many music teachers are convinced that their work contributes in important ways to certain fundamental concerns of society that cannot be addressed directly in the curriculum, such as developing young people who have good work habits, who are honest and decent, who care about their fellow human beings, and who are well adjusted and capable of leading satisfying and productive lives. This claim is probably true, though these outcomes are difficult to document and the evidence is largely anecdotal.

\section{Aesthetic Problems}

Another frequent objection to assessment from music teachers is that there is no easy way to evaluate aesthetic objects and responses. "How can you quantify the creative impulse?" teachers ask. "How can you express in test scores a child's love of beauty? How can you measure the transcendental experience of hearing a great musical work that sends shivers down the spine?"

The answer is that you can't. No one is being asked to do that. But it is possible to identify and evaluate the behaviors that reflect these traits and experiences. For example, it is clearly possible to assess the musical compositions or improvisations of youngsters. This is done regularly.

Teachers are seldom required to make subtle distinctions among works of uniform quality. Distin- guishing excellent, good, fair, and poor is normally sufficient. Typically, the judgments required are much more basic: Can this student carry a tune? Is that student playing the right notes? Is there any evidence of musical expression in this performance? Is that a reasonable description or a plausible analysis of this work? Is this the correct signature for the key of D major?

Any performances or behaviors can be categorized by levels of excellence. What is more important is helping students to form their own basis for assessment and thus become able to make similar assessments for themselves. In any case, the position that "You can't test what I teach" is no longer defensible.

\section{National Standards}

Efforts are currently underway to establish national norms and standards in several disciplines. The obstacles to developing national standards in music are formidable. It is difficult to develop objective standards for musical performance, and it is difficult to devise suitable methodologies for assessing certain other important musical skills and knowledge. Nevertheless, these obstacles can be overcome.

The Music Educators National Conference (MENC), the major professional organization in music education, has recommended general standards in many aspects of music teaching for several decades, and is now attempting to develop a frame- 
work for music education that will include more specific standards. The reintroduction of music into the National Assessment of Educational Progress will likely accelerate the movement toward national standards.

As we generate more and more data purporting to reflect educational outcomes, however, we should be increasingly cautious about how this information is used. Aggregate test data may be useful tools in public relations, but we must be careful not to become captives of our data.

We should remember that certain data may be irrelevant to our objectives. We should recognize that the data we have may reflect only what's easily measurable and not what's important. Let's be certain that we use our data to make intelligent decisions about education.

\section{Conclusion}

Despite formidable philosophical and practical problems, learning in music can and should be assessed along with the other learning taking place in the school. The task is particularly difficult in some musical settings, but it can be done.

At the same time, it should be pointed out that some things would be worth doing even if they could not be assessed at all. Music, for example, should be taught even if our students' progress could not be assessed.

The fundamental reason is simply that music exalts the human spirit. It enhances the quality of life. It brings joy, satisfaction, and fulfillment to every human being. Music is one of the most powerful, most compelling, and most glorious manifestations of every culture. It is the essence of civilization itself. It should never be neglected merely because it is difficult, or costly, or time-consuming to assess.

\section{Teens Show They Care by Volunteering}

Despite the contention by some that teenagers don't care about anyone else, a teen survey conducted by the Gallup Organization for Independent Sector reveals that 58 percent of American teenagers volunteered in 1989 .

These teens averaged 3.9 hours of volunteer time each week in activities such as babysitting, assisting the elderly and handicapped, or serving as an aide or assistant.

Fifty-two percent of the teen volunteers surveyed said they got involved through their schools and 10 percent said their schools required a certain number of hours of community service for graduation. 